\title{
ANATOMIA DA MADEIRA DE DUAS LEGUMINOSAS CESALPINIOÍDEAS DA FLORESTA ESTACIONAL DE MISIONES - ARGENTINA
}

\author{
GRACIELA INES BOLZON DE MUÑIZ1 JOSÉ NEWTON CARDOSO MARCHIORI²
}

\section{RESUMO}

São anatomicamente descritas e ilustradas com fotomicrografias as madeiras de Apuleia leiocarpa (Vogel) Macbride e Peltophorum dubium (Sprengel) Taubert.

Palavras-chave: Anatomia da madeira, Apuleia leiocarpa, Peltophorum dubium, Caesalpinioideae, Leguminosae.

\section{ABSTRACT}

The woods of Apuleia leiocarpa (Vogel) Macbride and Peltophorum dubium (Sprengel) Taubert are anatomically described and ilustrated with photomicrographs.

Key words: Wood anatomy, Apuleia leiocarpa, Peltophorum dubium, Caesalpinioideae, Leguminosae.

\section{INTRODUÇÃO}

O presente estudo trata da descrição anatômica da madeira de duas Leguminosas Cesalpinioídeas da Floresta Estacional de Misiones (Argentina): Apuleia leiocarpa (Vogel) Macbride, conhecida vulgarmente pelos nomes de grápia, grapia-puña, ivirá-piapuña ou iviráperé (Carvalho, 2003), e Peltophorum dubium (Sprengel) Taubert, a popular canafístula, ibirápitá ou árbol de Artigas (Lombardo, 1964).

De ampla distribuição geográfica no Brasil, a grápia é também encontrada no nordeste do Perú, no sul da Bolívia, no leste do Paraguai (Carvalho, 2003) e nas províncias argentinas de Misiones e Corrientes (Dimitri et al., 2000). Sua madeira, dura, moderadamente pesada e fácil de trabalhar, foi investigada tecnologicamente por Brotero (1956), Silva (1967) e Tortorelli (1956), tendo merecido deste último, inclusive, um detalhado estudo anatômico.

Nativa da Paraíba ao noroeste do Uruguai (Carvalho, 2003), a canafístula teve sua madeira estudada pelos mesmos autores acima referi- dos. Para a espécie, cabe ressaltar, ainda, as descrições macroscópicas de Tuset \& Duran (1970) e Steigleder (1971).

\section{MATERIAL E MÉTODOS}

O material estudado consiste da madeira de três árvores de cada espécie, procedentes de uma floresta da Universidad Nacional de Misiones, no Departamento de Guarani, Argentina. Extraído do alburno e à altura do peito, o referido material lenhoso foi incorporado ao acervo do Laboratório de Dendrologia da Facultad de Ciencias Forestales, da mesma Universidade.

De cada indivíduo foram preparados três corpos-de-prova, orientados para a obtenção de cortes anatômicos nos planos transversal, longitudinal radial e longitudinal tangencial. Após amolecimento por fervura em água, os corposde-prova foram seccionados em micrótomo Spencer AO n. 860, regulado para cortes com $18 \mu \mathrm{m}$ de espessura. Usou-se coloração com vermelho-de-acridina, crisoidina e azul de astra (Dujardin, 1964), desidratação em série alcoó-

\footnotetext{
1 Engenheira Florestal, Dra., Professora Titular do Departamento de Engenharia e Tecnologia Florestal, Universidade Federal do Paraná, CEP 80070-230, Curitiba (PR). gbmunize@ufpr.br

2 Engenheiro Florestal, Dr., Professor Titular do Departamento de Ciências Florestais, Centro de Ciências Rurais, Universidade Federal de Santa Maria, CEP 97105-900, Santa Maria (RS).balduinia@mail.ufsm.br
} 
lica e montagem permanente com "Entellan". $\mathrm{Na}$ maceração do tecido lenhoso, seguiu-se o método de Jeffrey (Freund, 1970); a pasta resultante foi tingida com safranina e usou-se $o$ mesmo meio de montagem.

Os dados quantitativos da estrutura anatômica foram processados diretamente em analisador de imagens "Videoplan", acoplado a computador, obtendo-se os respectivos valores mínimos, médios, máximos e desvio padrão (s), com o uso de programas aplicativos.

A descrição de elementos macroscópicos baseou-se na COPANT (1973). As mensurações de elementos celulares individuais e descrições microscópicas seguiram a ABNT, com as alterações introduzidas por Muñiz (1986). As fotomicrografias foram tomadas em aparelho Carl Zeiss, usando-se filme Kodak Panatomic $\mathrm{X}, \mathrm{ASA} 32$ e ampliações em papel fotográfico Kodabromid F-3 brilhante.

\section{DESCRIÇÃO DAS MADEIRAS}

\section{Peltophorum dubium (Sprengel) Taubert}

Caracteres gerais: Madeira de cerne castanho-rosado ou castanho-violáceo, com veios escuros irregulares e alburno rosado-claro, tendente a amarelo. Figura espigada bem definida, marcada pela direção irregular dos elementos vasculares e parênquima associado, que são de cor castanho-violácea-escura, contrastando com o tecido fibroso, castanho-claro e de textura lisa. Madeira dura, pesada $\left(0,85\right.$ a $\left.0,90 \mathrm{~g} / \mathrm{cm}^{3}\right)$, de textura média a grossa, heterogênea, e de grã diagonal até fortemente revessa.
Anéis de crescimento: Marcados por estreitas faixas de parênquima marginal e fibras achatadas de paredes mais espessas.

Vasos: Em porosidade difusa, principalmente solitários e de forma oval a circular; também em múltiplos radiais de 2 a 3 e escassos racemiformes de até 8 poros. Poros abundantes (3 a 8 por $\mathrm{mm}^{2}$ ), de $80-200-270 \mu \mathrm{m}$ de diâmetro $(\mathrm{s}=30,05)$ e paredes de 3-4-12 $\mu \mathrm{m}$ de espessura $(s=1,56)$. Linhas vasculares retilíneas até sinuosas. Elementos vasculares de 75-100$350 \mu \mathrm{m}$ de comprimento $(\mathrm{s}=3,76)$, freqüentemente com conteúdo escuro semelhante a resina. Placas de perfuração simples, transversais ou levemente oblíquas. Pontoações intervasculares ornamentadas, alternas, pequenas (5-8$11 \mu \mathrm{m})$ e circulares, com abertura lenticular inclusa. Pontoações radio-vasculares $(5-6-8 \mu \mathrm{m})$ e parênquimo-vasculares (4-6-7 $\mu \mathrm{m})$, semelhantes às intervasculares.

Parênquima axial: Tipicamente paratraqueal, dos tipos vasicêntrico, aliforme e confluente em curtas extensões oblíquas. Parênquima apotraqueal marginal em linhas uni ou bisseriadas, delimitando os anéis de crescimento e confundindo-se, em parte, com o parênquima paratraqueal; resta assinalar a existência de escasso parênquima apotraqueal difuso. Células parenquimáticas fusiformes ou em séries de 2 a 4, medindo 153-206-259 $\mu \mathrm{m}$ de altura $(\mathrm{s}=21,89)$ por $13-20-28 \mu \mathrm{m}$ de diâmetro. Séries cristalíferas freqüentes e em 2 a 10 câmaras, com monocristais romboédricos de oxalato de cálcio. 

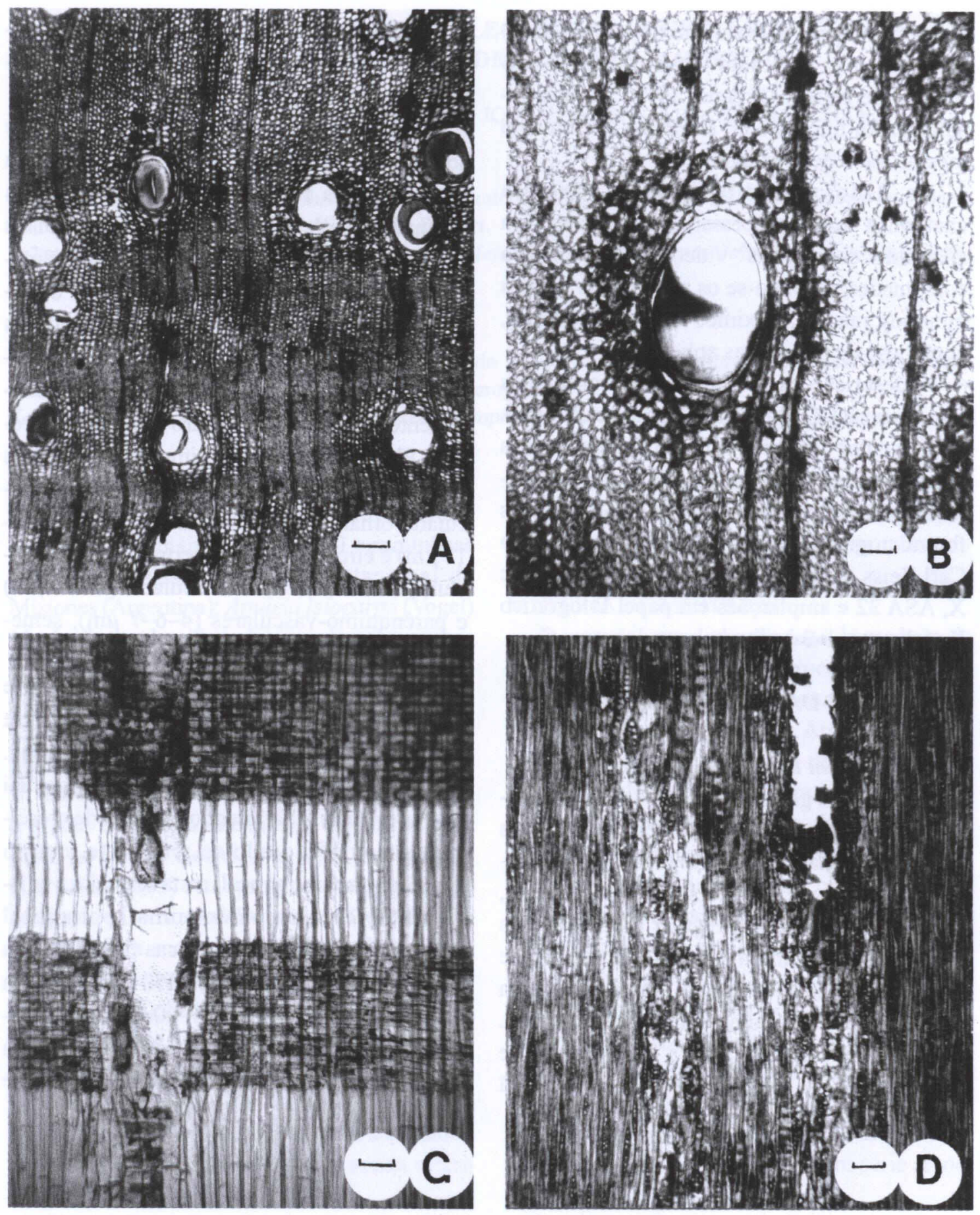

FIGURA 1 - Poros solitários e parênquima paratraqueal vasicêntrico até aliforme-confluente, em seção transversal (A). Detalhe de poro solitário e parênquima vasicêntrico, em seção transversal (B). Raios homogêneos, de células procumbentes, e fibras septadas, em seção raidial (C). Raios finos, em seção tangencial (D). Escalas $=100 \mu \mathrm{m}(\mathrm{A}, \mathrm{D}) ; 40 \mu \mathrm{m}(\mathrm{B}, \mathrm{C})$. 
Raios: Homogêneos, em número de 5 a 13/ $\mathrm{mm}$, compostos inteiramente de células procumbentes; são em geral bisseriados, havendo escassos trisseriados. Variam de 65-160-270 $\mu \mathrm{m}$ de altura $(\mathrm{s}=19,78)$ por $5-15-27 \mu \mathrm{m}$ de largura; os imersos no parênquima axial são mais largos.

Fibras: Libriformes, septadas e de seção poligonal ou arredondada. Medem 530-960 $1500 \mu \mathrm{m}$ de comprimento $(\mathrm{s}=32,60)$ por $13-$ $25-40 \mu \mathrm{m}(\mathrm{s}=2,45)$ de largura, tendo paredes muito espessas $(2-5-7 \mu \mathrm{m} ; \mathrm{s}=0,97)$.

\section{Apuleia leiocarpa (Vogel) Macbride}

Caracteres gerais: Cerne bege-amarelado, amarelo-rosado até castanho-rosado uniforme; alburno branco-amarelado. Madeira pesada $\left(0,78\right.$ a $\left.0,83 \mathrm{~g} / \mathrm{cm}^{3}\right)$, homogênea, de figura lisa, textura fina à média, brilho suave, grã direita, irregular ou até revessa e sem odor característico.

Anéis de crescimento: Pouco distintos, individualizados por zonas fibrosas ou finas linhas de parênquima marginal.

Vasos: Em porosidade difusa, solitários ou em múltiplos radiais e racemiformes de 2 a 4 , com seção circular, oval ou elíptica. Poros em número de $15 \mathrm{a} 35 / \mathrm{mm}^{2}$, com lume de $70-100$ $-130 \mu \mathrm{m}$ de diâmetro $(\mathrm{s}=26,76)$ e paredes espessas (4-6-12 $\mu \mathrm{m})$. Elementos vasculares estratificados, de 160-200-300 $\mu \mathrm{m}$ de comprimento $(s=32,56)$. Placas de perfuração simples. Pontoações intervasculares alternas, ornamentadas, circulares $(5-7-11 \mu \mathrm{m}, \mathrm{s}=0,78)$, com abertura elíptico-linear, inclusa; pontoações rádio-vasculares e parênquimo-vasculares, semelhantes.

Parênquima axial: Paratraqueal aliformeconfluente, por vezes incompleto ou unilateral, além do padrão marginal terminal. Células parenquimáticas de $180-220-250 \mu \mathrm{m}$ de altura $(\mathrm{s}=34,78)$ por $8-17-29 \mu \mathrm{m}$ de largura, em séries estratificadas de 3 ou 4 células e freqüentemente divididas em 2 a 8 câmaras, contendo grânulos irregulares de sílica ou monocristais romboédricos de oxalato de cálcio.

Raios: Estratificados, em número de 9 a 11/ $\mathrm{mm}$. Raios fracamente heterogêneos, com células procumbentes na parte central e uma fileira marginal de células procumbentes mais curtas $\mathrm{e}$ altas, ou então células quadradas até eretas. Raios em sua maioria bisseriados, com poucos unisseriados e trisseriados; medem 150-235$300 \mu \mathrm{m}(\mathrm{s}=27,34)$, com até 13 células de altura. Estratificação regular; estratos de aproximadamente $245 \mu \mathrm{m}$ de altura, acompanhando elementos vasculares e parênquima axial.

Fibras: Libriformes e de seção poligonal até arredondada, medindo 600-1050-1450 $\mu \mathrm{m}$ de comprimento $(\mathrm{s}=109,45)$, por $11-17-30 \mu \mathrm{m}$ de diâmetro, com paredes espessas (8-16-30 $\mu \mathrm{m}, \mathrm{s}=1,45)$.

\section{ANÁLISE DA ESTRUTURA ANATÔMICA}

As duas espécies estudadas apresentam elementos vasculares muito curtos a curtos, placas de perfuração simples, pontuado intervascular alterno, pontoações ornamentadas de tamanho pequeno a médio e parênquima paratraqueal, aspectos referidos por Cozzo (1951), Metcalfe \& Chalk (1972), Record \& Hess (1949) e Tortorelli (1956), como muito característicos na família Leguminosae. O parênquima aliforme, observado em ambas as espécies, é mais freqüente nas sub-famílias Mimosoideae e Caesalpinioideae, embora igualmente observado em algumas Papilionoideae. $\mathrm{O}$ padrão apotraqueal difuso e cristalífero, por sua vez, é importante caráter diagnóstico nas Mimosoideae, menos comum nas Caesalpinioideae e relativamente raro nas Papilionideae (Metcalfe \& Chalk, 1972). 

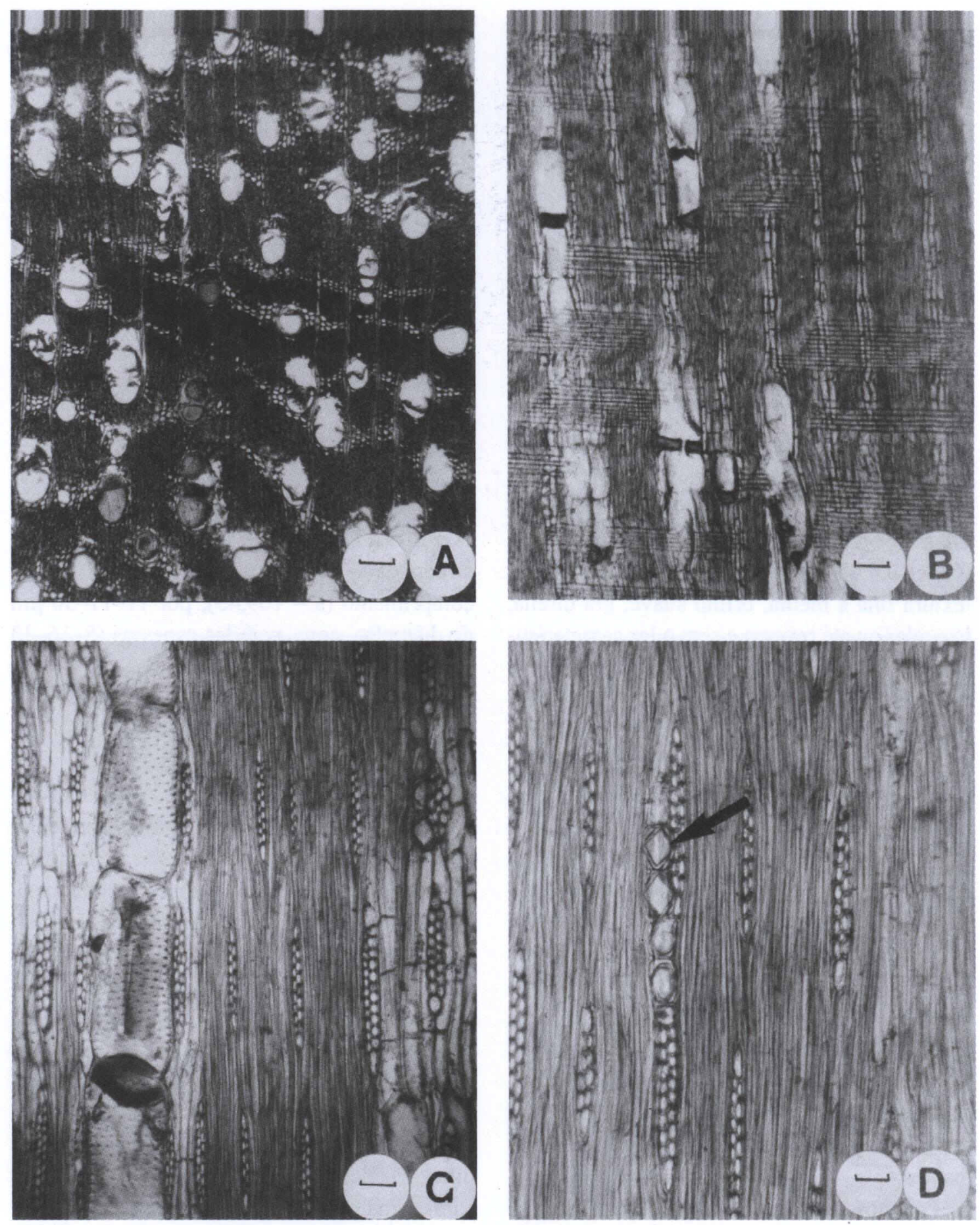

FIGURA 2 - Poros solitários, parênquima aliforme-confluente e anel de crescimento marcado por linha de parênquima marginal, em seção transversal (A). Tecido radial heterogêneo, em seção radial (B). Estratificação de raios, parênquima axial e elementos vasculares, em seção tangencial (C). Cristais de oxalato de cálcio em câmaras, em seção tangencial (D). Escalas = $100 \mu \mathrm{m}$ (A, B); $40 \mu \mathrm{m}$ (C); $25 \mu \mathrm{m}$ (D). 

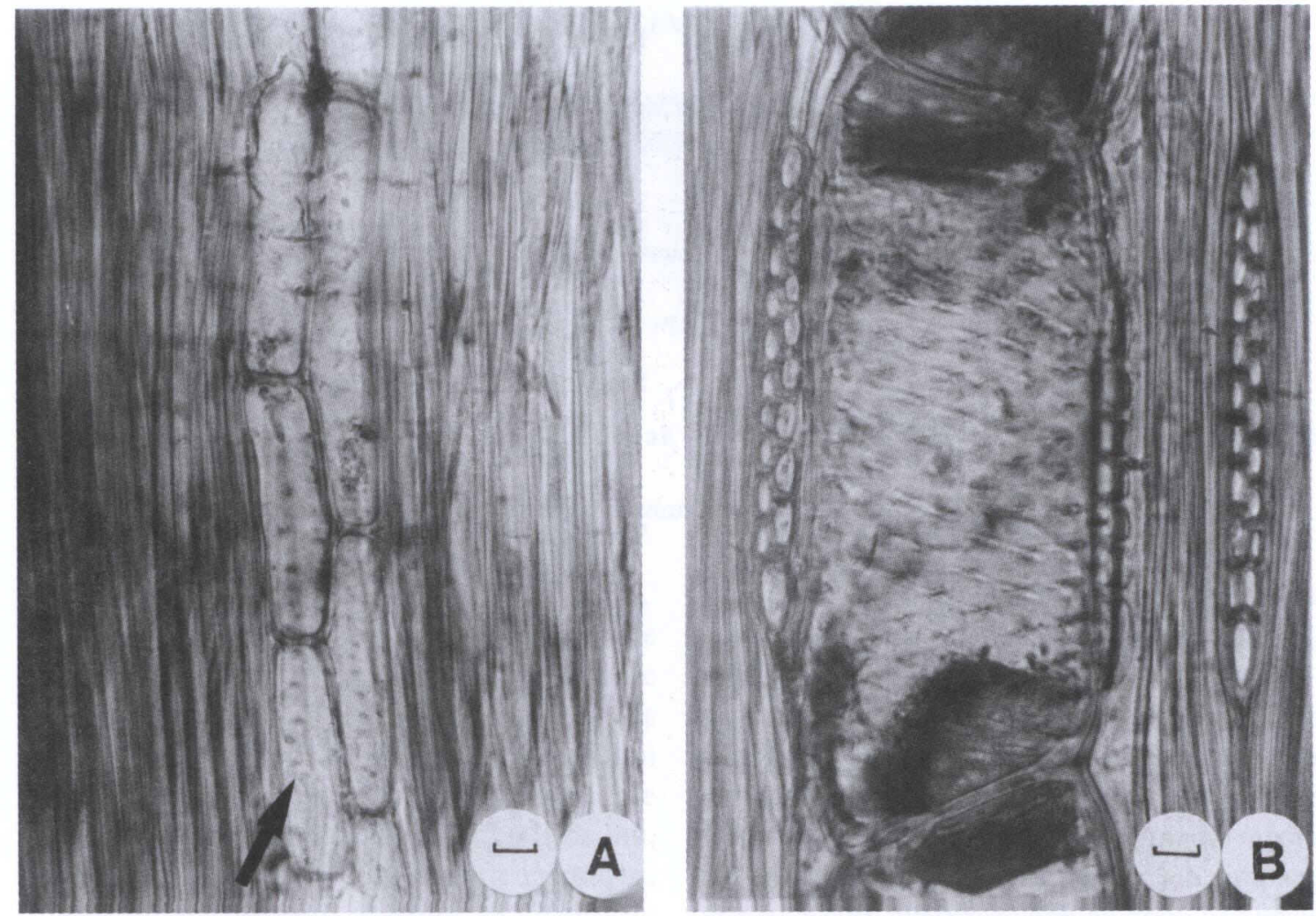

FIGURA 3 - Grânulos irregulares de sílica (seta), no parênquima axial, em seção radial (A). Pontoações intervasculares ornamentadas, em seção tangencial (B). Escalas $=12,5 \mu \mathrm{m}$.

Os vasos em Apuleia leiocarpa têm diâmetro significativamente menor do que em Peltophorum dubium; a freqüência de poros, ao contrário, é nitidamente maior na primeira do que na última dessas espécies, permitindo uma fácil separação entre as mesmas. Tais aspectos, sabidamente relacionados ao habitat característico das espécies, denota mesomorfia ao lenho de Peltophorum dubium e está de acordo com a conhecida preferência da grápia por encostas ou chapadas, locais "onde a drenagem dos solos é bastante elevada" (Reitz, Klein \& Reis, 1983).

Quanto ao comprimento de elementos vasculares, os valores mínimos e máximos não permitem uma nítida separação entre as espécies; mesmo assim, o valor médio do caráter em Peltophorum dubium corresponde à metade do verificado em Apuleia leiocarpa.

\section{BIBLIOGRAFIA}

Brotero, F. A. Tabelas de resultados obtidos para madeiras nacionais. São Paulo : Instituto de Pesquisas Tecnológicas, 1956. 28p. (Boletim n. 31). Carvalho, P. E. R. Espécies arbóreas brasileiras. Brasília: Embrapa Informação Tecnológica, 2003. v. 1.1039 p.

Copant - Comissão Panamericana de Normas Técnicas. Descrição macroscópica e geral da madeira - esquema I de recomendação. Colômbia, 1973. 19 p. (COPANT 30).

Cozzo, D. Anatomia del leño secundario de las leguminosas mimosoideas y caesalpinoideas argentinas silvestres y cultivadas. Rev. Inst. Nac. Invest. Ci. Nat. C. Bot., Buenos Aires, v. 2, n. 2, p. 63-290, 1951.

Dimitri, M. J., Leonardis, R. F. J., Biloni, J. S. EI nuevo libro del arbol. Buenos Aires: El Ateneo, 2000. v. 2.124 p. 
Dujardin, E. P. Eine neue Holz-zellulosenfaerbung. Mikrokosmos, n. 53, p. 94, 1964.

Freund, H. Handbuch der Mikroskopie in der Technik. Frankfurt: Umscham Verlag, 1970.375p. Lombardo, A. Flora arborea y arborescente del Uruguay. Montevideo: Concejo Departamental, 1964. $151 \mathrm{p}$.

Metcalfe, C. R., Chalk, L. Anatomy of the Dicotyledons. Oxford: Clarendon Press, 1972. $1500 \mathrm{p}$.

Muñiz, G. I. B. Descrição da estrutura e ultraestrutura da madeira de cinco espécies de Prosopis da Argentina e análise da metodologia. Curitiba: UFPR, 1986. 192 f. Dissertação (Mestrado em Engenharia Florestal) Universidade Federal do Paraná.

Muñiz, G. I. B. Anatomia da madeira de espécies arbóreas da Floresta Estacional Semidecidual de Misiones, Argentina. Curitiba, UFPR, 1993. 152 f. Tese (Concurso de Professor Titular) Universidade Federal do Paraná.
Record, S. J., Hess, R. W. Timbers of the New World. New Haven: Yale University Press, 1949. 640 p.

Reitz, R., Klein, R. M., Reis, A. Projeto Madeira do Rio Grande do Sul. Sellowia, Itajaí, n. 34-35, p. 300, 1983.

Silva, P. F. da. Características físico-mecânicas de espécies lenhosas do sul do Brasil. Porto Alegre : Instituto Tecnológico do Rio Grande do Sul, 1967. 41p. (Boletim n. 42).

Steigleder, M. de V. Madeiras do sul do Brasil (Macrografia). Porto Alegre: Instituto Tecnológico do Rio Grande do Sul, 1971. 59 p. (Boletim n. 54).

Tortorelli, L. A. Maderas y bosques argentinos. Buenos Aires: ACME, 1956. 910 p.

Tuset, R., Duran, F. Descripcion y clave macroscopicas de madeiras comerciales en Uruguay. Montevideo: Universidad de la Republica, Facultad de Agronomia, 1970. 63 p. (Boletim n. 114). 